\title{
Organização do trabalho, prazer e sofrimento de docentes públicos federais
}

\author{
Graziele Alves Amaral ${ }^{1}$, Amanda Leal Borges ${ }^{2}$, Ana Paula de Melo Juiz ${ }^{3}$ \\ Universidade Federal de Goiás (Jataí, GO)
}

\begin{abstract}
O panorama de crescimento nos últimos anos de números de vagas e de professores do ensino superior aponta para a necessidade de maior atenção à qualidade do ensino e à saúde no trabalho dos docentes. Esta pesquisa, de caráter descritivo, buscou compreender a relação entre organização do trabalho e as vivências de prazer e sofrimento de docentes de um campus de interior de uma universidade federal a partir da análise psicodinâmica do trabalho. Foram realizadas entrevistas semiestruturadas com cinco docentes, e os dados foram submetidos à análise de conteúdo. Constatou-se demonstração de prazer no trabalho por meio de atividades de ensino e pesquisa e do relacionamento com os alunos. As vivências de sofrimento referem-se às situações de conflitos interpessoais e à falta de infraestrutura e sobrecarga no trabalho. Por vezes esses sofrimentos puderam ter um destino criativo, através da mobilização da inteligência prática, da autonomia e da satisfação sublimatória propiciada pelo significado do fazer docente.
\end{abstract}

Palavras-chaves: Trabalho docente, Psicodinâmica do Trabalho, Prazer e sofrimento no trabalho.

Work organization, pleasure and suffering of the public federal professors

In the last few years, the increase in vacancies and lecturers number showed the necessity to pay attention to the education's quality and the professors' health. This research has descriptive character and aimed to understand the relationship between work organization and pleasure and suffering experiences of professors from a countryside campus of a federal university, using the psychodynamic analysis of work. Semi-structured interviews were done with five professors and the data were analyzed using the technique of content analysis. The study verifies demonstration of pleasure at working through education and research activities and the relationship with students. The suffering experiences refer to interpersonal conflicts and bad infrastructure and overload in the job. Sometimes these sufferings could have a creative destination, through the mobilization of practical intelligence, autonomy and the sublimatory satisfaction provided by the meaning of teaching work.

Keywords: Teaching work, Psychodynamics of work, Pleasure and suffering at work.

\section{Introdução}

\begin{abstract}
A s mudanças do mundo do trabalho a partir da reestruturação produtiva dos anos 1970 e 1980, com a flexibilização da economia e a implantação da ideologia neoliberal, trouxeram impactos para toda a classe trabalhadora, atingindo inclusive os professores universitários. A lógica neoliberal, baseada na política de retração do Estado, trouxe como consequências a redução de políticas públicas, o desmonte de mecanismos de distribuição de renda, a supremacia dos interesses do sistema financeiro e a privatização dos serviços públicos. O novo sistema produtivo, que a partir daí se impôs, precisa ser capaz de atender às flutuações de um mercado cada vez mais flexível e exigente, trazendo aos trabalhadores a necessidade de produzir novas performances (Mancebo, 2007). Segundo a autora, a flexibilização trouxe consigo o fim do horário regular de trabalho, o aumento do trabalhado em tempo parcial, temporário ou subcontratado, além de requisição contínua de novas qualificação aos trabalhadores. Com isso, verificam-se níveis salariais cada vez mais baixos,

1 Doutora em Psicologia Social, do Trabalho e das Organizações pela Universidade de Brasília, DF. Professora adjunta do curso de Psicologia da Universidade Federal de Goiás, regional Jataí.

2 Analista de recursos humanos na Lacel Laticínios Ceres, Goiânia, GO. Graduada em Psicologia pela Universidade Federal de Goiás, regional Jataí.

3 Support worker no Hales Group, Inglaterra. Graduada em Psicologia pela Universidade Federal de Goiás, regional Jataí.
\end{abstract}


aumento do desemprego, perda dos direitos trabalhistas, insegurança no emprego e intensificação dos processos de trabalho. Nesse contexto, impõe-se às universidades que elas se adequem às novas demandas desse modelo econômico, que pretende transformá-las em mais uma organização do mercado (Coutinho, Dal Magro \& Budde, 2011).

Houve considerável aumento do número de docentes no ensino superior federal por efeito de programas do governo como o Reuni (Programa de Apoio a Planos de Reestruturação e Expansão das Universidades Federais), que teve como principal objetivo ampliar o acesso e a permanência na educação superior. Outro programa do governo nessa linha foi a Expansão da Rede Federal de Educação Superior, que teve início em 2003 com a interiorização dos campi das universidades federais e já possibilitou a criação de mais de 100 novos campi (Brasil, 2010). Borsoi (2012) aponta que houve uma elevação significativa da demanda de trabalho docente nos últimos vinte anos e um acréscimo insignificante do número de docentes efetivos nas universidades federais. Desse modo, sem desconsiderar a importância do aumento quantitativo das universidades públicas, é preciso analisar a qualidade do que se tem criado, tanto na perspectiva da qualidade do ensino e da pesquisa quanto na perspectiva de seus impactos para a saúde dos docentes. É devido a esse último enfoque que esta pesquisa se justifica.

O aumento do trabalho docente em extensão e intensidade é outra questão importante quanto às mudanças na rotina das atividades docentes, podendo ser observado, por exemplo, pelo significativo aumento do número de alunos em relação aos docentes. Nesse caso, Bosi (2007) aponta um aumento de 50\% na média do número de alunos para cada professor entre os anos de 1998 e 2004, demonstrando um crescimento do quantitativo de discentes desproporcional ao aumento do número de docentes no âmbito das universidades públicas. $\mathrm{O}$ autor ainda aponta que a pressão exercida sobre esses professores para que sejam produtivos (aulas, orientações, projetos, publicações), quantificada e qualificada por critérios informados de fora da universidade, culmina por ferir um princípio básico da universidade pública: a autonomia. Demandas contraditórias lhes são impostas: assumindo uma imensa quantidade de trabalho na graduação e de atividades administrativas, muitas vezes se veem impossibilitados de desenvolver projetos de pesquisa e/ou extensão, sendo assim considerados improdutivos pelos órgãos superiores da universidade e/ou pelos órgãos de fomento (Lima, 2011).

Na perspectiva da Psicodinâmica do Trabalho (PdT), Mendes (2007b) analisa as consequências das novas formas de organização do trabalho no contexto da acumulação flexível e da reestruturação produtiva e atesta a existência de patologias sociais relacionadas ao trabalho. Dentre elas, destaca a sobrecarga como uma patologia em que o jogo de dominação social regido pela ideologia da excelência e do desempenho faz os trabalhadores se submeterem a demandas que vão além de suas condições físicas ou psicológicas. Seja pela disciplina da fome em que o sentido do trabalho é o "ganha-pão", seja pela centralidade do trabalho, que leva à necessidade de realização e reconhecimento pelo trabalho, o trabalhador assume a postura de considerar que todas as possibilidades de trabalho devem ser aproveitadas. Nessa direção, observa-se ainda a patologia da servidão voluntária, que se refere ao consentimento de certas práticas de trabalho, inclusive as que geram sofrimento e baseadas no conformismo e na submissão sem protestos, como forma de se apresentar como um trabalhador adaptado, integrado e eficaz. Ambas as patologias, consentidas e legitimadas pela naturalização e banalização do sofrimento e das injustiças, possibilitam ao capital a exploração do trabalhador, transformando seu sofrimento em produtividade.

O docente universitário não está imune ao produtivismo. Existe um esforço desse trabalhador para ser considerado como pertencente a uma classe elitizada, o que se consegue a partir da participação em programas de pós-graduação e do número de orientações, artigos e livros publicados (Bosi, 2007).

A teoria da PdT é a base que fundamenta este estudo sobre a análise das vivências dos docentes no seu trabalho. Ela é uma abordagem de pesquisa desenvolvida nos anos 1990, na 
França, por Christophe Dejours e tem como objeto "o estudo das relações dinâmicas entre a organização do trabalho e processos de subjetivação" (Mendes, 2007a, p. 30), sendo central para isso, a compreensão sobre como a organização do trabalho mobiliza e engaja o sujeito em sua dinâmica. Segundo Dejours (1996), a organização do trabalho compreende, de um lado, a divisão de tarefas em seu modo operatório, que atinge a questão do interesse e do tédio no trabalho; por outro lado, engloba a divisão dos homens, em que estão incluídas questões da hierarquia e das relações de poder, atingindo as relações que os trabalhadores estabelecem no trabalho.

Nessa abordagem, trabalhar implica "os gestos, saber fazer, um engajamento do corpo, a mobilização da inteligência, a capacidade de refletir, de interpretar e de reagir às situações; é o poder de sentir, de pensar e de inventar", referindo-se, portanto, ao "engajamento da personalidade para responder a uma tarefa delimitada por pressões (materiais e sociais)" (Dejours, 2004, p. 28). Para o autor, trabalhar é sempre preencher a lacuna entre o trabalho prescrito e o trabalho real, sendo o prescrito aquilo que é predeterminado por regras, regulamentos e manuais, que nunca dá conta do real, ou seja, as prescrições nunca são abrangentes o suficiente para abarcarem a realidade concreta da situação de trabalho. Assim, o trabalho se define por aquilo que o sujeito trabalhador deve acrescentar às prescrições para alcançar os objetivos que lhe são designados pela organização do trabalho.

Essa mobilização também pode ser entendida como sofrimento, referindo-se a uma série de mecanismos de regulação do psiquismo, ou seja, um estado de luta do sujeito contra as forças adoecedoras ligadas à organização do trabalho. Segundo Dejours e Abdoucheli (2009), a presença do sofrimento não implica, necessariamente, existência de doença. Portanto, existem dois tipos de sofrimento relativos à organização do trabalho: o criativo e o patogênico. $\mathrm{O}$ sofrimento patogênico acontece quando não há mais nenhuma margem de liberdade que o sujeito possa explorar para transformar ou aperfeiçoar a organização do trabalho, pois as pressões são rígidas, fixas e incontornáveis, levando o trabalhador à repetição e gerando nele desgaste, frustração, sentimento de impotência e, até mesmo, adoecimento. O sofrimento criativo, por seu turno, acontece quando o sofrimento pode ser transformado em criatividade, contribuindo, então, para a resistência do sujeito à desestabilização. Nesse caso, o trabalho seria favorável à saúde do trabalhador. De acordo com Mendes (2007a, p. 34), "para transformar um trabalho que faz sofrer em um trabalho prazeroso, é necessário que a organização do trabalho propicie maior liberdade ao trabalhador para rearranjar seu modo operatório, usar sua inteligência prática, engajar-se no coletivo", de modo que seja possível identificar ações capazes de promover vivências de prazer. Outra possibilidade de o trabalho favorecer o equilíbrio mental é quando seu conteúdo é fonte de satisfação sublimatória. Em ambos os casos, as dificuldades são facilmente aceitas, pois, mesmo que o trabalho gere algum sofrimento, o prazer de sua realização permite ao sujeito uma melhor defesa (Dejours, 1992).

A relação do sujeito com a organização do trabalho pode levar a vivências de prazer e de sofrimento, na medida em que a subjetividade do sujeito trabalhador dá um sentido às suas vivências laborais. Quando nessas vivências impera o sofrimento, e o trabalhador não tem possibilidade de ressignificá-lo, estratégias defensivas são formuladas para evitar o adoecimento ou amenizar o sofrimento causado pelo trabalho (Silva \& Freitas, 2011). Elas surgem quando o trabalhador consegue transformar o modo como ele vivencia sua realidade de trabalho que lhe causa sofrimento, criando novas formas de lidar com o seu cotidiano, mesmo que isso não gere mudanças em seu ambiente de trabalho real (Mendes, 2007a). A ressalva é que, na medida em que elas funcionam como uma "anestesia", permitindo ignorar o sofrimento e negar suas causas, podem se tornar um mecanismo de alienação, podendo levar a patologias sociais (Mendes \& Duarte, 2013).

Mendes (2007b) ressalta que, mesmo em um contexto em que as condições de trabalho são precárias, é possível vivenciar o prazer quando a organização do trabalho permite que o trabalhador desenvolva a mobilização da inteligência prática e quando há espaço público da fala e da cooperação. 
A mobilização da inteligência prática refere-se à ruptura das regras para se alcançar o trabalho prescrito na busca de soluções criativas para as situações reais do trabalho. $\mathrm{O}$ espaço público da fala ocorre quando os trabalhadores têm abertura para manifestar publicamente sua opinião e serem ouvidos pelos demais. Nesse sentido, os trabalhadores criam um espaço e compartilham práticas e/ou vivências de trabalho na organização, podendo assim serem reconhecidos. A cooperação é uma construção conjunta para produzir uma ideia, serviço ou produto; passa pela construção de solidariedade e confiança entre os integrantes do grupo. Nessas circunstâncias, as vivências de sofrimento podem se transformar em sofrimento criativo.

Partindo desses princípios, a atividade docente em universidades públicas pode ser vista como um tipo de trabalho cuja natureza ainda propicia a vivência de prazer. Coutinho et al. (2011) ressaltam que o que se observa é que as atuais características do trabalho do professor universitário podem levá-lo a experimentar um paradoxo em relação aos sentimentos suscitados. De um lado, há sofrimento relacionado à precarização das condições de trabalho e de outro, prazer pela possibilidade de produção do conhecimento, pelo reconhecimento obtido no espaço acadêmico e pela autonomia na realização de suas atribuições. Nesse sentido, esse trabalho pode proporcionar identidade, realização, reconhecimento e liberdade, permitindo ao trabalhador ser sujeito da ação e não um sujeito dominado pelo trabalho, conforme apontado por Mendes (2007b) como condições de vivência de prazer no trabalho.

Sofrimento e prazer não são propriedades mutuamente excludentes. Na relação do sujeito com o trabalho observa-se a coexistência desses polos, na medida em que um pode ser transformar no outro ou ambos podem existir ao mesmo tempo. $\mathrm{O}$ sofrimento, inerente à existência humana, pode tomar um caminho patogênico ou criador (Neves \& Silva, 2006). Na atividade docente, as autoras afirmam que através de estratégias reguladoras os professores podem dar uma resposta criativa ao sofrimento que o trabalho provoca na medida em que investem na transformação da realidade. O sentido do trabalho apresenta-se como aspecto fundamental para a vivência do prazer, uma vez que não se configura apenas como satisfação (que estaria ligada ao atendimento das necessidades), mas como realização.

É com base nessa perspectiva que se propôs nesta pesquisa compreender a relação entre a organização do trabalho e as vivências de prazer e de sofrimento de docentes de um campus do interior de uma universidade pública federal, baseando-se na perspectiva da PdT. Para isso, foi necessário examinar as atividades realizadas pelos docentes dessa instituição, analisando as responsabilidades atribuídas a esses profissionais e sua relação com seu trabalho. Buscou-se também compreender a hierarquia e as relações profissionais vivenciadas por esses docentes e como eles percebem e vivenciam as condições de trabalho.

\section{Método}

Esta pesquisa é de natureza qualitativa, que se caracteriza por seu aspecto compreensivo e interpretativo, possibilitando a compreensão das inter-relações que emergem de um dado contexto (Alves-Mazzotti \& Gewandsznajder, 1999). O estudo de caso com docentes de um campus de interior de uma universidade pública federal foi adotado como técnica de estudo restrita a uma ou poucas unidades, tendo como características a profundidade e o detalhamento (Vergara, 2014).

Os critérios para a busca de sujeitos de pesquisa foram: ser docente do quadro efetivo de um campus do interior da universidade pública federal estudada há pelo menos três anos (período correspondente ao estágio probatório). Os sujeitos foram convidados a partir da rede de conhecidos de uma das pesquisadoras (desde que atendidos os critérios enunciados) e as entrevistas foram realizadas a partir da disponibilidade em fornecerem as informações. Além disso, com o objetivo de 
deixar a amostra mais heterogênea, foi entrevistado um docente de cada uma das cinco grandes áreas do conhecimento presentes no campus em questão: Ciências Exatas, Ciências Humanas, Ciências Biológicas, Linguística e Ciências Agrárias. Entre os entrevistados, três eram homens e duas eram mulheres. O tempo de trabalho na instituição variou de quatro a catorze anos. $\mathrm{O}$ encerramento da busca por novos participantes se deu em razão de a equipe pesquisadora considerar que as perguntas de pesquisa foram respondidas.

Para a coleta de dados, utilizou-se a entrevista semiestruturada, fundamentada nas categorias da Análise Psicodinâmica do Trabalho (APDT). A duração média de cada entrevista foi de 1 hora e 10 minutos. Elas foram realizadas entre os meses de agosto e outubro de 2013.

Mendes e Araújo (2012) propõem a Análise Clínica do Trabalho (ACT) como um método para organizar o material coletado nas sessões coletivas, sendo constituída por três etapas, quais sejam: Análise dos Dispositivos Clínicos (ADC), APDT e Análise da Mobilização do Coletivo de Trabalho (AMCT). No caso desta pesquisa, como não foram realizados encontros coletivos, mas uma adaptação do método da clínica psicodinâmica do trabalho, com a utilização de entrevistas individuais, foi seguida apenas Etapa II do método, APDT. Essa etapa corresponde à estruturação de três eixos de análise. O Eixo I diz respeito à organização do trabalho prescrito e do trabalho real, contemplando os seguintes temas: tipos de tarefas; divisão do trabalho; normas e regras; tempos e ritmos; exigências técnicas; relações com pares, chefias e clientes; estilo de gestão; responsabilidades e riscos. O Eixo II diz respeito à mobilização subjetiva e contempla os seguintes temas: sofrimento criativo; inteligência prática; espaço de discussão; cooperação; reconhecimento. O Eixo III referese ao sofrimento, às defesas e às patologias e inclui os temas: sofrimento patogênico; estratégias de defesas individuais; estratégias de defesas coletivas; tipos de patologias; danos físicos e psicossociais.

A análise dos dados se deu por meio dos procedimentos sistemáticos da análise de conteúdo de Bardin (1977), que consiste em uma série de técnicas de análise das comunicações, buscando a descrição do conteúdo das mensagens que permitam a inferência de conhecimentos dentro da abordagem utilizada para amparar esta pesquisa.

As entrevistas foram gravadas, transcritas na íntegra e geraram o material a ser analisado. A análise foi feita pelas três pesquisadoras. As categorias construídas resultaram da investigação das entrevistas, com abertura das pesquisadoras para conhecer o que pudesse emergir das narrativas. A análise dos dados se iniciou com a codificação dos temas das entrevistas, que foram nomeados e discutidos entre a equipe. Além das diretrizes de análise de conteúdo, os três eixos da APDT também foram norteadores para a sistematização e a interpretação dos dados. Os temas foram agrupados em categorias, a partir da familiaridade do seu conteúdo.

A pesquisa foi aprovada pelo Comitê de Ética da Universidade Federal de Goiás sob o protocolo de número 136/2013.

\section{Resultados}

A apresentação dos resultados foi organizada a partir dos três eixos norteadores da APDT: organização do trabalho prescrito e o real do trabalho; mobilização subjetiva; e sofrimento, defesas e patologias (Mendes \& Araújo, 2012).

\section{Resultados referentes ao Eixo I}

No que se refere ao trabalho prescrito, a resolução do conselho universitário da referida instituição, estabelece as atividades constituintes do trabalho do professor divididas em cinco categorias: as atividades de ensino (que compreendem as aulas ministradas na graduação e/ 
ou pós-graduação), a produção intelectual (que abrange produção científica, artística/cultural, técnica/tecnológica), pesquisa e extensão (coordenação de projetos de ensino e extensão), atividades administrativas e de representação (que engloba funções de reitoria, pró-reitoria, coordenador de curso, presidência de comissões etc.), e outras atividades (incluindo orientações, participação em bancas e concursos e atividades de aperfeiçoamento).

Em consonância com toda essa abrangência do rol de atividades docentes, os professores descreveram a diversidade de suas tarefas, deslizando entre as responsabilidades do tripé "ensino, pesquisa e extensão", além das atividades administrativas e de outras atribuições extras, como: participação em bancas e apresentação de trabalhos em eventos científicos.

Não existe uma rotina diária em relação ao cumprimento das atividades laborais, pois depende da forma como estão distribuídas tais atribuições ao longo da semana e das demandas que vão surgindo. Para a realização das atividades de trabalho, muitas vezes os três turnos do dia (manhã, tarde e noite) são ocupados. Há uma prática comum de levar trabalho para ser realizado em casa, não só como forma de aproveitar o terceiro turno de trabalho, mas devido à inadequação da estrutura de trabalho na universidade: "Eu trabalho muito, muito, mas eu faço tudo em casa. Aqui não tem muita estrutura, você não tem privacidade para trabalhar" (S2).

A assunção de uma carga horária cada vez mais extensa em relação às atividades administrativas tem sido vista como uma obrigação muitas vezes penosa, tanto pelo excesso de atividades dessa natureza, como pela falta de preparo para exercê-las: "É uma coisa que não me dá prazer, mas a universidade cada vez mais tem jogado para nós, coisas administrativas que não são da docência" (S3). A falta de preparo em relação a atividades próprias da docência também foi apontada em situações mais extremas, como ter que assumir uma sala de aula com 110 alunos na primeira experiência de trabalho na universidade. Outra situação presente foi a sobrecarga de trabalho de professores que retornavam de licença doutoral, momento em que se sentiam compelidos a "compensar" o tempo de afastamento.

Na realização das atividades, os entraves burocráticos são grandes dificultadores e impedem a fluidez do trabalho. Como fator adicional, ainda existe a dependência do campus do interior em relação ao campus sede, o que incrementa a burocracia e interfere na autonomia para a realização das atividades de trabalho e para as tomadas de decisão. Por outro lado, os professores sentem que têm autonomia em relação à cobrança de chefia, dada a natureza da gestão de uma universidade pública.

A relação com os alunos é satisfatória e na maioria das vezes respeitosa, sendo fonte de prazer. Existe a preocupação dos docentes em assumirem uma postura equilibrada com os discentes, que não seja paternalista, mas que também não seja autoritária.

A relação com os pares foi descrita de uma forma geral como tensa, com falta de coesão entre os colegas de trabalho, divergências de ideias e luta por recursos, que acabam gerando discussões e defesa de interesses particulares. Mas dentro de pequenos subgrupos, existe vivência de um relacionamento interpessoal mais coeso e cooperativo: "Existe um grupo, pequeno grupo, que são solidários com pequenas coisas" (S3).

Dentre as relações com os pares, a relação com a coordenação de curso possui uma especificidade: apesar da denominação "coordenação", o professor que assume essa função não tem poder de chefia sobre os professores de seu colegiado, sendo muito mais uma figura administrativa do que uma chefia. De qualquer forma, na universidade em questão muitas vezes o professor coordenador de curso acaba utilizando essa função para ameaçar seus pares e exercer uma autoridade que não lhe caberia. Por outro lado, houve professores relatando relação harmônica com seus pares que estão na função de coordenação de curso.

No que se refere às relações hierárquicas, como se trata de um campus que não possui separação dos cursos em departamentos, quem exerce a gestão direta sobre os docentes é a direção do campus, composta pelo diretor, o vice-diretor e mais cinco assessores de cada uma das seguintes 
áreas: graduação, pesquisa e pós-graduação, extensão, comunicação e assuntos estudantis. Para fins desta pesquisa, entende-se a gestão da universidade como a forma que a diretoria do campus (mais especificamente, o diretor) administra os recursos da instituição e as pessoas envolvidas. Nessa gestão, uma de suas principais responsabilidades é a intermediação do campus com as instâncias deliberativas da sede da universidade. Nesse quesito, a interlocução com toda a comunidade universitária do campus (incluindo docentes, técnico-administrativos e discentes) é uma tarefa de fundamental importância que não estava sendo cumprida a contento pela atual gestão, segundo a avaliação dos professores entrevistados. Destaca-se a falta de consideração pelas pessoas como grande gerador de mal-estar no trabalho, o que também afeta a qualidade do trabalho: "Isto é grave quando você está fazendo uma gestão que não contempla ou não considera as pessoas. [...] Respeitar o próximo é a coisa mais simples do mundo. Isto não está sendo considerado em nenhuma esfera do campus" (S1).

A centralização nas tomadas de decisões, a falta de preparo em relação a questões administrativas dos professores que estão em cargos de gestão e a dependência do campus do interior em relação ao campus sede são outros problemas que se refletem na gestão da universidade. A falta de preparo dos gestores, além de trazer problemas no que tange à administração de recursos, ainda gera dificuldades no trato com as pessoas: os professores percebem que há a adoção de uma postura defensiva que dificulta o diálogo, como forma de se esconder a insegurança e a inexperiência. Sobre a dependência do campus sede, a distância impede que se compreendam as reais necessidades do campus do interior, sendo essa situação vivenciada como negligência e descaso por parte dos professores entrevistados e a possibilidade de se tornar uma universidade independente uma solução aventada: "a gente tem que traçar uma estratégia para conseguir os requisitos mínimos para emancipar essa universidade. Aí nós vamos ter orçamento, não vamos depender [da sede]. Não vamos fazer números pra eles, mas pra nós. Aí vamos nos estruturar melhor" (S5).

As condições de trabalho são um grande problema para os docentes: muitas vezes, falta o mínimo de estrutura física de trabalho, além da insuficiência do número de professores e de técnico-administrativos, o que interfere na qualidade do trabalho: "Falar de estrutura aqui é surreal. Não tem estrutura" (S1); "Eu sinto muita falta. São coisinhas básicas, mas que são irritantes e que acabam atrapalhando a qualidade do que a gente oferece para os alunos" (S2).

As más condições de trabalho impactam também nas relações interpessoais, já que há disputa pelos recursos escassos que são disponibilizados, além do fato de que, pela falta de salas de professores, a maioria realiza grande parte do trabalho em casa. Observa-se a busca individual por soluções, como a concorrência por verbas de editais das agências de fomento de pesquisa. A inadequação e a insuficiência das condições de trabalho são vistas como incompatíveis com o nível de exigência em relação ao trabalho do professor universitário.

\section{Resultados relativos ao Eixo II}

No Eixo II, que se refere à mobilização subjetiva, observa-se a vivência do prazer no trabalho ligada ao significado da docência. Apesar das dificuldades impostas, os entrevistados sentem prazer nas atividades de ensino e de pesquisa: "O que eu mais gosto é fazer pesquisa. Principalmente porque eu trabalho em campo. Então, eu conheço muitos lugares [...] quando eu consigo publicar os artigos. Isto é o que mais me motiva: quando você tem reconhecimento dos alunos" (S5); "Eu escolhi a docência como profissão, primeiro por ter o prazer, a satisfação de fazer pesquisa. [...] Orientar aluno e pesquisa são as duas coisas mais prazerosas" (S1).

O relacionamento com os alunos é gratificante tanto nas situações de sala de aula quanto em atividades de orientação, além de possibilitar gratificação pela percepção de contribuição na formação profissional dos discentes "Eu gosto de ver meus alunos brilhando. Eles saem das nossas mãos 
aqui e dão certo. [...] Eu acho que a docência em si é muito gratificante no sentido de que você partilha muito, é muito enriquecedora" (S2); "Com os alunos, saber orientá-los, estimulá-los, é o mais importante. Eu acho que eu já assumi a docência como um papel social interessante" (S1). Nesse sentido, a relação com alunos possibilita acessar o reconhecimento do trabalho docente, elemento constituinte da mobilização subjetiva.

A inteligência prática é exercida na relação com o aluno, no sentido de ajudá-lo a descobrir seu potencial, e também na relação com os pares, ao conseguirem resolver com fluidez situações que normalmente ficariam sem solução. Além disso, há mobilização da inteligência prática quando extrapolam a falta de estrutura e de recursos e conseguem alcançar os resultados desejados. Mas, muitas vezes, essas situações ocorrem de maneira isolada, sem mobilização do coletivo; enquanto classe profissional, não percebem cooperação, sendo mais comum vivenciarem o não envolvimento dos pares na busca por melhorias mais amplas nas condições de trabalho. Em pequenos subgrupos, é possível observar situações de cooperação entre os pares em projetos específicos ou na divisão do trabalho, mas quando essa análise é levada para um grupo maior (como os professores de um determinado curso, por exemplo), observa-se a sobrecarga de alguns devido ao não envolvimento de outros.

Em termos de reconhecimento, ressalta-se a presença de reconhecimento por parte dos alunos. Também foi relatado o reconhecimento do público em situações de apresentação de trabalhos em eventos científicos.

No que diz respeito ao espaço de discussão coletivo, apenas um sujeito relatou as reuniões de colegiado como espaço de escuta e de resolução de problemas: "Então, as questões que a gente acha que não estão bem claras, a gente resolve tudo na coordenação em reuniões. Lá é aberto, todo mundo fala o que pensa, sente" (S4).

\section{Resultados relativos ao Eixo III}

Em relação aos elementos do Eixo III - sofrimento, defesas e patologias - há relatos de vivência de sofrimento em algumas situações de trabalho, mas não houve relatos de patologias instaladas. Um fator em comum citado como fonte de sofrimento foi a participação em reuniões. Em termos práticos, essas reuniões (departamentais e, principalmente, as reuniões do conselho deliberativo) são desgastantes por não serem fluidas e resolutivas, trazendo para os sujeitos a sensação de perda de tempo. Para além desse motivo prático, as reuniões costumam ser situações de muitos embates - muitas vezes até desrespeitosos para com os colegas de trabalho - e de defesas de interesses individuais e não coletivos. O clima dessas reuniões tem repercussões para os docentes; para alguns, tem trazido o sentimento de incapacidade de participar desses encontros, tamanha a carga ansiogênica sentida: "Todas as sextas-feiras que tem reunião. Isto me faz sofrer demais, sofro muito, muito, muito, muito." (S1); "Acho que estes embates acabam comigo. Na universidade tudo dá briga, tudo. Tudo tem que ser brigado, no tapa. Isso me incomoda muito" (S3). Ainda que essa situação seja geradora de sofrimento, algumas vezes há a possibilidade de não participar dessas reuniões, por exemplo, recusando-se a assumir determinados cargos administrativos nos quais a presença em reuniões deliberativas é obrigatória: "Eu não pego a direção ou estes cargos administrativos porque me incomodam muito estes embates" (S3).

Existe sofrimento vivenciado pela sobrecarga de trabalho, o que pode gerar tanto sintomas relativamente simples - tais como dor de cabeça pelo acúmulo de noites mal dormidas - quanto a sensação de que se está, ao longo do tempo, perdendo a energia e a disposição que se tinha para trabalhar, situação relatada por apenas um dos sujeitos: "Eu tenho perdido o pique. Estou cansada, chegando a momentos que eu não quero fazer. Eu acho isso ruim, não é meu. Eu tenho esse fogo que me impulsiona a fazer. Eu não caí a produção, mas caí por dentro" (S2). 
Em relação às defesas individuais, existe a tentativa de resolução dos problemas institucionais de forma individualizada, como a prática de adquirir, com recursos próprios ou advindos de editais das agências de fomento, materiais ou equipamentos que deveriam ser disponibilizados pela universidade. Observam-se discordâncias em relação a essa prática: há os que pensam que ela pode trazer conforto e praticidade na resolução de algumas lacunas referentes às condições de trabalho e os que discordam desse comportamento por ele desmobilizar a luta por melhores condições. "Se eu fosse depender da universidade, seriam péssimas [as condições de trabalho], mas eu consigo verba através de pesquisas" (S5); "Não temos uma estrutura de trabalho [..], não é coerente com as exigências. Tem gente que traz coisas de casa [...]; as pessoas acabam cedendo. Mas eu ainda não cedi a isso ainda não, espero não ter que ceder" (S3).

Ainda em relação às estratégias de enfrentamento individuais, observa-se a postura de desistência em relação ao envolvimento com questões mais amplas da universidade: "Não vale a pena eu gastar esforço para dar murro em ponta de faca" (S5). Também foi relatada a tentativa de manutenção do bom humor para enfrentar as dificuldades rotineiras de trabalho. A adoção de uma postura mais enrijecida e combativa tem sido outra estratégia de enfrentamento adotada nas relações socioprofissionais. A possibilidade de pedir exoneração para dar um fim ou um novo rumo ao sofrimento também foi relatada: "Exoneração. Essa palavra rondou muito na minha cabecinha" (S1). Por outro lado, observa-se uma postura menos combativa e de gratidão por parte de um docente que foi formado pela instituição de ensino em que trabalha hoje. Não foram observadas estratégias de defesa coletivas.

\section{Discussão}

Na prática, as dimensões da organização do trabalho estão interligadas, e em todas elas pode haver elementos geradores de sofrimento e/ou condições de mobilização subjetiva e, consequentemente, de vivência de prazer. A PdT se interessa pela relação do sujeito com o trabalho prescrito e com as contradições entre o trabalho prescrito e o trabalho real. E nessa relação, observase a coexistência das vivências de prazer e de sofrimento, como foi possível perceber no caso dos docentes entrevistados. A seguir, os elementos dos Eixo I da APDT (organização do trabalho e trabalho real) serão discutidos a partir de seus efeitos sobre os elementos do Eixo II (mobilização subjetiva) e do Eixo III (sofrimento, patologias e defesas).

No que se refere à inter-relação entre a organização do trabalho prescrito e o real com a mobilização subjetiva, observa-se forte identificação dos docentes com o seu trabalho. Ou seja, o trabalho é fonte de significado para esses trabalhadores. A relação com os alunos e a responsabilidade que esses docentes sentem que têm no processo de amadurecimento intelectual e pessoal dos discentes traz sentido ao fazer docente. Dessa forma, o exercício da docência permite a vivência do sofrimento criativo pelo seu poder transformador, tanto para os alunos quanto para a sociedade de uma forma geral. Esses resultados corroboram com os de outros estudos que identificaram vivências de prazer associadas à identidade de ser professor e ao reconhecimento que se tem no trabalho a partir desse significado social da docência (Coutinho et al., 2011; Mendes, Chaves, Santos \& Neto, 2007; Moraes, 2005; Neves \& Silva, 2006).

Pelo significado que os docentes entrevistados atribuem ao seu trabalho, é possível compreendêlo como fonte de satisfação sublimatória. A sublimação, entendida como uma estratégia defensiva bem-sucedida, por permitir a canalização de energia pulsional para atividades socialmente aceitas, pode explicar como esses professores têm lidado com as adversidades em seu contexto de trabalho, mantendo sua saúde psíquica, encontrando alternativas criativas para responder às exigências do trabalho e vivenciando situações de prazer no trabalho. Quando o trabalho assume o sentido de sublimação da energia, passa representar uma atividade prazerosa (Dejours, 1992). 
O prazer com a realização de pesquisas também foi ressaltado por todos os docentes. A atividade de pesquisa foi destacada por permitir mostrar os resultados de seu trabalho por meio de publicações e da participação em eventos científicos, obtendo reconhecimento da comunidade científica. Outra questão mencionada foi o fato de a pesquisa permitir parceria com os alunos. No trabalho, as vivências de prazer ocorrem quando há mobilização subjetiva, composta pelas dimensões inteligência prática, espaço de discussão, cooperação e reconhecimento (Mendes \& Duarte, 2013). Percebe-se que as atividades mencionadas como prazerosas possibilitam a mobilização subjetiva pela via do reconhecimento da comunidade científica e dos alunos e pela mobilização da inteligência prática, dada a natureza do trabalho docente.

Na pesquisa de Fleury (2013) com docentes de uma universidade federal, também foi possível perceber o relacionamento com os alunos como grande fonte de prazer, sendo esse relacionamento gratificante também em virtude do valor social que a docência representa. Freitas (2013) destaca nos estudos encontrados sobre a dinâmica do prazer-sofrimento no trabalho de docentes a importância do sentimento de utilidade e de responsabilidade dos professores por sua participação na formação de cidadãos. Neves e Silva (2006) apontam que o prazer é evocado na relação que os docentes têm com os alunos e no fato de perceberem o resultado de seu trabalho, o que remete à dimensão afetiva existente na relação educativa. Moraes (2005) também salienta como uma das principais fontes de prazer do trabalho docente a troca afetiva com os alunos envolvida na tarefa de educar, já que o produto do trabalho do professor é a transformação que acontece com o aluno.

Ainda sobre experiências prazerosas no trabalho, a autonomia foi relatada como fator relevante. Destaca-se aqui a importância da flexibilidade na organização do trabalho para a mobilização da inteligência prática e, como consequência, a vivência de prazer no trabalho. A atividade docente possibilita o exercício da criação e da autonomia, que são inerentes ao processo de ensino-aprendizagem (Borsoi, 2012; Coutinho et al., 2011). Um fator relevante encontrado na pesquisa diz respeito às estratégias encontradas pelos docentes para lidarem com o sofrimento e os constrangimentos no trabalho. A respeito dessa possibilidade saudável de lidar com o sofrimento através da mobilização da inteligência prática, Moraes (2005, p. 170) afirma: "Quando o trabalho apresenta condições desafiadoras e o professor consegue lançar-se a elas, alcançando o que julgava inatingível, a fonte original de sofrimento transforma-se em fonte de prazer". Por outro lado, pelos resultados desta pesquisa, há que se atentar que a sensação de que a autonomia está ameaçada pela dependência do campus do interior em relação ao campus sede foi relatada pelos docentes entrevistados como um fator de descontentamento.

No que diz respeito ao espaço de discussão coletivo, houve uma única menção das reuniões de colegiado como um espaço de escuta e de resolução de problemas. No entanto, isso não pode ser considerado como um espaço de escuta do sofrimento, pois foi ressaltado como um espaço de discussões e trocas mais voltadas para o âmbito técnico. Desse modo, os docentes carecem de um espaço de discussão coletivo.

Mas há menção sobre relações de cooperação entre subgrupos, formando pequenas redes que facilitam a realização do trabalho e os relacionamentos socioprofissionais. Se, por um lado, o pertencimento a um subgrupo fornece suporte social, por outro, conflitos entre os subgrupos são fontes de sofrimento. Mas às vezes é possível dar um novo destino a esse sentimento: neste estudo, S1 relatou se sentir sozinho e boicotado no trabalho, o que o tem feito pensar na possibilidade de pedir exoneração. Apesar de ser uma decisão radical, essa possibilidade não parece desestabilizar sua saúde mental, pois o sujeito vê uma saída para o conflito que vivencia no trabalho e não pensa na exoneração por medo ou ameaça, mas por vislumbrar alternativas mais saudáveis.

Os entrevistados destacaram as reuniões do conselho deliberativo como desencadeadoras de sofrimento, pois esses encontros geram discussões agressivas e em muitos momentos acarretam conflitos que corroem a convivência socioprofissional. As disputas pelos parcos recursos distribuídos 
geram rivalidade entre os colegas de trabalho: "Acho que é um ambiente muito pesado, tem horas que você vê pessoas desagradando as outras de maneira até áspera" (S4). Nesse contexto, a solidão impera e a desestruturação dos coletivos de trabalho pode levar a mecanismos de defesa tais como práticas desleais com os colegas e condutas agressivas baseadas no individualismo e na falta de consideração pelo outro (Mendes, 2007b). Ainda que os entrevistados tenham relatado vivências desprazerosas nessas situações de trabalho, não foi possível observar patologias relacionadas ou desestabilização psíquica. A liberdade, ainda existente no trabalho desses docentes, dá a eles alguma margem de negociação em relação à organização do trabalho, possibilitando aos que mais se afetam com os conflitos presentes, principalmente no contexto das reuniões deliberativas, não assumirem cargos administrativos que os exponham constantemente a tais situações.

A escassez de recursos no contexto de trabalho gera impactos nas relações profissionais e contribui para levar os professores a buscarem entre eles mesmos os culpados por essa situação (Fleury, 2013), quando na verdade a responsabilidade seria institucional. Diante dessas adversidades estruturais, os docentes buscam formas práticas para amenizar o sofrimento advindo desse contexto. Alguns optam por comprar por conta própria os recursos que necessitam para garantir um trabalho mais eficaz e um ambiente mais confortável fisicamente, utilizando-se, assim, do individualismo como forma de amenizar esse sofrimento. Essa estratégia também foi observada diante das adversidades estruturais do ambiente de trabalho no estudo de Fleury (2013) com docentes, ao considerar que as estratégias defensivas, além de terem a função de adaptação e proteção do sujeito contra o sofrimento, podem também se transformar numa ideologia de defesa e levar à alienação. Ao invés de buscarem mudanças na organização do trabalho, os sujeitos podem se acomodar por meio do uso dessas defesas (Mendes \& Duarte, 2013).

Diante desse cenário de estrutura precária de trabalho, alguns docentes assumem uma postura mais questionadora e relatam que não aceitam adquirir com recursos próprios materiais/equipamentos que a universidade deveria lhes oferecer, por mais que isso lhes trouxesse maior conforto. Embora esse tipo de posicionamento tenha sido encontrado, não se configura como um movimento coletivo de mobilização.

Ainda sobre os problemas com falta de estrutura, a carência de salas de professores faz com que eles levem o trabalho para seu ambiente doméstico. Essa flexibilidade de trabalho acaba gerando sobrecarga, já que o trabalho em casa não tem limites e os sujeitos estão pressionados pelo controle internalizado. A falta de tempo dedicado ao lazer compromete a dinâmica familiar. Há a possibilidade de que patologias da sobrecarga (Mendes, 2007b) passem a fazer parte do cotidiano desses docentes. Na pesquisa de Borsoi (2012) com docentes da Universidade Federal do Espírito Santo, a necessidade de concluir tarefas pendentes devido à sobrecarga de trabalho fazia com que permanecessem em atividade fora do horário de trabalho prescrito, interferindo no tempo que se dedicariam a necessidades particulares.

Em outro estudo, a sobrecarga marcadamente presente no cotidiano dos docentes universitários, muitas vezes atrelada à necessidade de alguns professores assumirem atividades administrativas, também foi um dos achados (Fleury, 2013). Tal sobrecarga, além de deslocar o foco do docente de atividades mais diretamente ligadas à docência, gera conflitos interpessoais com outros professores que não se comprometem com o funcionamento da universidade. Aqueles docentes que mais se engajam nas tarefas políticas e administrativas da universidade não recebem o reconhecimento esperado e podem receber mais sobrecarga de trabalho decorrente de uma maior dedicação. Há que se destacar a armadilha nessa relação sem limites com as demandas do trabalho: o trabalhador, nesse caso, o professor, pode se envolver cada vez mais com o trabalho na busca por reconhecimento, que dificilmente acontece; então, em busca de mais reconhecimento, mais demandas vão sendo aceitas (Freitas, 2013).

Borsoi (2012) ainda analisa outro aspecto importante no que se refere à sobrecarga de trabalho: muitas atividades que ocupam tempo significativo dos docentes são consideradas desnecessárias, 
sendo um entrave na produção acadêmica. No caso desta pesquisa, observa-se o incômodo dos docentes com os entraves burocráticos e institucionais, ainda reforçados pela dificuldade de se resolverem questões simples em razão de o campus estar localizado fora da Sede Administrativa. Críticas foram apontadas pelos docentes no que se refere à postura centralizadora que a direção do campus e alguns professores em função de coordenação de curso assumem na tomada de decisões e na relação com os pares. A adoção desse tipo de posicionamento foi atribuída ao despreparado das pessoas que assumiram cargos de gestão e à disseminação de relações desrespeitosas no ambiente das universidades, não só nas relações hierárquicas, mas nas relações entre pares. Borsoi (2012) alerta para o fato de que a universidade pública, ao adotar práticas de gestão baseadas em critérios produtivistas e de estímulo à competição, pode impactar a qualidade da produção acadêmica e a saúde do docente. Isso porque o trabalho do docente realiza-se na dimensão imaterial, e ele não pode ser avaliado e nem cobrado com base nessa perspectiva produtivista, sob a pena de trazer custos à sua saúde e às suas relações profissionais.

A ampliação do ensino superior sem a devida atenção à qualidade do que está sendo produzido e ampliado, traz repercussões para a subjetividade e para as relações de trabalho dos docentes. Percebe-se uma política de expansão condizente com uma lógica instrumental, caracterizada pela certificação em massa e pela minimização de custos e maximização da produtividade. Ou seja, constata-se a insuficiente contratação de docentes diante do aumento de cursos e matrículas, culminando em uma expansão precarizada, sofrimento para os professores e conflitos em suas relações de trabalho, principalmente nos campi do interior (Silva, 2013). A qualidade da educação pública superior brasileira depende da elaboração e execução de políticas públicas que efetivamente cuidem da saúde física e mental dos professores (Freitas, 2013).

O que pode ser percebido nesta pesquisa é que os professores entrevistados relatam com criticidade e insatisfação suas condições de trabalho, apontando para a precarização do ensino superior público, principalmente no contexto de um campus do interior. Também foi possível observar que, assim como apontado na pesquisa de Coutinho et al. (2011, p. 164), "se por um lado, as condições e formas de organização das atividades profissionais são geradoras de sofrimento, por outro, não conseguem apagar o registro da identidade associado ao ser professor". Por isso, ainda que se tenham identificado no trabalho situações de sofrimento, há que se destacar as estratégias que os professores têm utilizado para lidar com as dificuldades e o sofrimento e as possibilidades estruturantes que o trabalho está trazendo.

Neves e Silva (2006) ressaltam que a permanente reconfiguração dos desejos dos sujeitos e sua consequente demanda por novas melhorias fazem com que não se possa pensar em um local de trabalho onde as condições de trabalho sejam ideais no sentido de garantia da saúde. Nesse sentido, a saúde seria um ideal que está sempre à nossa frente. Portanto, mesmo que não seja possível encontrar um ofício de inteiro prazer, os professores relatam com indignação suas condições de trabalho, não só como forma de denúncia da precarização, mas também como forma de lutar pela sua saúde psíquica em um trabalho que lhes é repleto de significados e de prazer.

\section{Considerações finais}

Esta pesquisa objetivou compreender a relação entre a organização do trabalho e as vivências de prazer e sofrimento de docentes de um campus do interior de uma universidade pública federal a partir da perspectiva da PdT. Para isso, foram realizadas entrevistas semiestruturadas com cinco docentes.

Constatou-se que dentre os fatores de prazer no trabalho se destacam: as atividades de ensino e as relações interpessoais com os alunos - questões ligadas ao significado do ser docente; as atividades

\section{6}


de pesquisa que possibilitam a utilização da inteligência prática; e o reconhecimento da comunidade científica. Por outro lado, as vivências de sofrimento no trabalho referem-se às seguintes situações: falta de infraestrutura, sobrecarga por atividades administrativas, conflitos interpessoais e mal-estar em relação à condução da gestão. Por vezes, observa-se que esses sofrimentos puderam ter um destino criativo, através da mobilização da inteligência prática e da autonomia ainda presente no contexto de trabalho de docentes de universidades federais. Isso tem possibilitado a eles encontrar saídas práticas para as dificuldades e para alguns constrangimentos no trabalho. Além disso, o significado do fazer docente e o conteúdo da maioria de suas atividades é fonte de satisfação sublimatória, propiciando vivência de prazer no trabalho.

Esses docentes utilizam, principalmente, o individualismo como uma estratégia defensiva. Mas outras estratégias defensivas mais saudáveis do ponto de vista psíquico também puderam ser observadas, como o humor e a gratidão.

A insatisfação com as condições de trabalho e suas consequências foram questões bastante presentes nos relatos dos entrevistados, sendo entendida como uma forma de denúncia da precarização das universidades públicas federais, principalmente as dos campi do interior, mas também como forma de lutar pela sua saúde psíquica em um trabalho que lhes é repleto de significado e de prazer. Há a esperança de que a emancipação do campus da sede possa amenizar os problemas estruturais e, consequentemente, melhorar a organização do trabalho.

Esta pesquisa pode contribuir para refinar a análise do panorama propagado de crescimento nos últimos anos em números de vagas e de professores do ensino superior sob a ótica desses trabalhadores que atuam nesse contexto. Quando o tema é tratado da perspectiva de um campus de interior, são mostradas algumas nuances dessa realidade nova e ainda pouco estudada. A qualidade do ensino depende da saúde no trabalho dos docentes, e assim, observa-se a necessidade de se atentar para que o prazer com o trabalho e o engajamento observado entre esses trabalhadores não seja minado nesse processo de precarização da educação superior pública brasileira.

\section{Referências}

Alves-Mazzotti, A. J. \& Gewandsznajder, F. (1999). O método nas ciências naturais e sociais: pesquisa quantitativa e qualitativa. São Paulo: Pioneira.

Bardin, L. (1977). Análise de conteúdo. Lisboa: Edições 70.

Borsoi, I. C. F. (2012). Trabalho e produtivismo: saúde e modo de vida de docentes de instituições públicas de Ensino Superior. Cadernos de Psicologia Social do Trabalho, 15 (1), 81-100.

Bosi, A. P. (2007). A precarização do trabalho docente nas instituições de ensino superior do Brasil nesses últimos 25 anos. Educação e Sociedade, 28 (101), 1503-1523.

Brasil (2010). Ministério da Educação e Cultura. O que é Reuni. MEC, Brasília, DF, 2010. Disponível em: goo.gl/ MZCen3 [18 março 2013]

Coutinho, M. C., Dal Magro, M. L. P. \& Budde, C. (2011). Entre o prazer e o sofrimento: um estudo sobre os sentidos do trabalho para professores universitários. Psicologia: Teoria e Prática, 13 (2), 154-167.

Dejours, C. (1992). A loucura no trabalho: estudo de psicopatologia do trabalho (5ae ed). São Paulo: Cortez; Oboré.

Dejours, C. (1996). Uma nova visão do sofrimento humano nas organizações. In J. F. Chanlat (Coord.). O indivíduo na organização: dimensões esquecidas (vol. 1, pp. 149-173). São Paulo: Atlas.

Dejours, C. (2004). Trabalho, subjetividade e ação. Produção, 14 (3), 27-34.

Dejours, C. \& Abdoucheli, (2009) Itinerário teórico em psicopatologia do trabalho. In M. I. S. Betiol (Coord.). Psicodinâmica do trabalho: contribuições da escola dejouriana à análise da relação prazer, sofrimento e trabalho (pp. 119-145). São Paulo: Atlas. 
Fleury, A. R. D. (2013). O trabalho e a docência em uma instituição de ensino superior pública: o caso dos professores de Odontologia da Universidade Federal de Goiás. Tese de Doutorado, Programa de Pós-Graduação em Psicologia, Universidade Católica de Goiás, Goiânia.

Freitas, L. G. (2013). Docentes, seu trabalho e a dinâmica de prazer-sofrimento. In L. G. Freitas (Coord.), Prazer e sofrimento no trabalho docente: pesquisas brasileiras (pp. 35-47). Curitiba: Juruá.

Lima, K. (2011). As novas faces da intensificação do trabalho docente no Brasil. In Anais do V Encontro Brasileiro de Educação e Marxismo, Educação e Emancipação Humana. Florianópolis: UFSC.

Mancebo, D. (2007) Trabalho docente: subjetividade, sobreimplicação e prazer. Psicologia: Reflexão e Crítica, 20 (1), 74-80.

Mendes, A. M. (2007a). Da psicodinâmica à psicopatologia do trabalho. In Mendes, A. M. (Org.) Psicodinâmica do trabalho: teoria, método e pesquisas (pp. 29-48). São Paulo: Casa do Psicólogo.

Mendes, A. M. (2007b). Novas formas de organização do trabalho, ação dos trabalhadores e patologias sociais. In Mendes, A. M. (Org.) Psicodinâmica do trabalho: teoria, método e pesquisas. São Paulo: Casa do Psicólogo.

Mendes, A. M. \& Araújo, L. K. R. (2012). Clínica psicodinâmica do trabalho: o sujeito em ação. Curitiba: Juruá.

Mendes, A. M. \& Duarte, F. S. (2013). Notas sobre o percurso teórico da psicodinâmica do trabalho. In Freitas, L. G. (Coord.) Prazer e sofrimento no trabalho docente: pesquisas brasileiras (pp. 13-24). Curitiba: Juruá.

Mendes, L., Chaves, C. J. A., Santos, A. C. \& Neto, G. A. R. M. (2007). Da arte ao ofício: vivências de sofrimento e significado do trabalho de professor universitário. Mal-estar e Subjetividade, 7 (2), 527-556.

Moraes, R. D. (2005). Prazer e sofrimento no trabalho docente: estudo com professores de ensino fundamental em processo de formação superior. Psicologia: Organizações e Trabalho, 5 (1), 159-183.

Neves, M. Y. R. \& Silva, E. S. (2006). A dor e a delícia de ser (estar) professora: trabalho docente e saúde mental. Estudos e Pesquisas em Psicologia, 6 (1), 63-75.

Silva, E. P. (2013). Sofrimento psíquico no trabalho do professor da Universidade Pública. In L. G. Freitas (Coord.) Prazer e sofrimento no trabalho docente: pesquisas brasileiras (pp. 71-92). Curitiba: Juruá.

Silva, F. H. E. \& Freitas, L. G. (2011). Organização do trabalho, prazer-sofrimento e estratégias de mediação no trabalho de programadores de faculdade via internet. In A. M. Mendes, A. R. C. Merlo, C. F. Morrone \& E. P. Facas (Org.), Psicodinâmica e clínica do trabalho: temas, interfaces e casos brasileiros (pp. 433-450). Curitiba: Juruá.

Vergara, S. C. (2014) Projetos e relatórios de pesquisa em administração (15ª ed.). São Paulo: Atlas.

\section{Endereço para correspondência}

graziamaral@yahoo.com.br, amandaleal60@yahoo.com.br, anapaula.meju@gmail.com
Enviado em: 26/01/2016

Revisado em: 11/07/2017

Aprovado em: 08/11/2017 